\title{
Cianobactérias marinhas bentônicas de ilhas costeiras do Estado de São Paulo, Brasil
}

\author{
LILIAN MOS BLOIS CRISPINO ${ }^{1,2,3}$ e CÉLIA LEITE SANT’ANNA²
}

(recebido: 18 de agosto de 2005; aceito: 9 de novembro de 2006)

\begin{abstract}
Marine benthic cyanobacteria of coastal islands, São Paulo State, Brazil). Marine benthic Cyanobacteria have always been neglected by taxonomic surveys of the Brazilian coast, exception made for some works focusing the shore of the São Paulo State. For island habitats there is only one study carried out for the Cardoso Island. Therefore, the aim of this study is to improve the knowledge about the richness of cyanobacterial species in marine benthic communities from coastal islands of the São Paulo State. The results show the occurrence of 24 species of Cyanobacteria: Oscillatoriales are represented by 12 species $(50 \%)$, Nostocales by 6 species $(25 \%)$ and Chroococcales by 6 species $(25 \%)$. Among the identified species, four represent new references for the South Atlantic: Cyanodermatium gonzaliensis H. Leon-Tejera et al., Xenococcus pallidus (Hansg.) Komárek \& Anagn., Microchaete aeruginea Batters and Hydrocoryne spongiosa Bornet \& Flahault, and one is a new occurrence for the coast of Brazil: Rivularia atra Roth. Some nomenclatural updatings were adopted according to the Komárek \& Agnostidis more recent system of classification.
\end{abstract}

Key words - benthic Cyanobacteria, coastal islands, São Paulo, taxonomy

RESUMO - (Cianobactérias marinhas bentônicas de ilhas costeiras do Estado de São Paulo, Brasil). O grupo das cianobactérias marinhas bentônicas vem sendo freqüentemente excluído dos levantamentos taxonômicos da costa brasileira, com exceção de alguns trabalhos para o litoral paulista. Para o ambiente de ilhas, apenas é conhecido um trabalho para a Ilha do Cardoso. Assim, o objetivo deste estudo consiste em ampliar o conhecimento da riqueza das cianobactérias marinhas bentônicas de ilhas do litoral paulista. Os resultados obtidos mostram a ocorrência de 24 espécies de cianobactérias em ilhas do litoral paulista. A ordem Oscillatoriales foi representada por 12 espécies (50\%), Nostocales por 6 espécies (25\%) e Chrooccoccales por seis espécies (25\%). Entre as espécies identificadas, quatro são novas ocorrências para o litoral Atlântico sul: Cyanodermatium gonzaliensis H. Leon-Tejera et al., Xenococcus pallidus (Hansg.) Komárek \& Anagn., Microchaete aeruginea Batters and Hydrocoryne spongiosa Bornet \& Flahault e uma nova referência para o litoral brasileiro: Rivularia atra Roth. Atualizações nomenclaturais foram adotadas de acordo com o sistema de classificação mais atual de Komarek \& Agnostidis.

Palavras-chave - Cyanobacteria bentônica, ilhas costeiras, São Paulo, taxonomia

\section{Introdução}

O grupo das cianobactérias vem sendo freqüentemente excluído das floras e levantamentos taxonômicos de comunidades marinhas, tanto para o Estado de São Paulo, como para o litoral brasileiro em geral. Existem poucos trabalhos que tratam exclusivamente do grupo, fazendo-se necessário um estudo amplo e detalhado da biodiversidade das cianobactérias do litoral brasileiro. Os estudos da biodiversidade das cianobactérias marinhas bentônicas realizados por Halperin $(1967,1970,1974)$ no litoral da Argentina contribuíram muito para o conhecimento da diversidade do grupo no Atlântico sul. Para o litoral brasileiro, os estudos realizados por Sant'Anna et al.

\footnotetext{
1. Parte da tese de doutorado do primeiro autor, Programa de Pós-Graduação do Instituto de Botânica, SP.

2. Instituto de Botânica, Caixa Postal 4005, 01061-970 São Paulo, SP, Brasil.

3. Autor para correspondência:1mbcrispino@hotmail.com
}

(1985), Baeta-Neves (1991, 1992), Baeta-Neves \& Tribuzi (1992), Sant'Anna \& Simonetti (1992), Sant'Anna et al. (1995), Sant'Anna $(1995,1997)$ e, em manguezal, por, Nogueira \& Ferreira-Correia (2001) e Branco et al. (2003), resumem quase todo o conhecimento existente sobre as cianobactérias marinhas bentônicas.

Em relação às ilhas do litoral paulista, não existem informações sobre a flora de cianobactérias. A única exceção é a Ilha do Cardoso, localizada no extremo sul do Estado, onde foi realizado o trabalho de Sant'Anna (1995), que descreve e ilustra 30 espécies marinhas bentônicas. Além deste, existem alguns estudos sobre cianobactérias de manguezais da ilha nos quais foram identificados e descritos 38 táxons (Branco et al. 1996, 1997). Há ainda um trabalho sobre uma espécie nova de Stichosiphon típica de manguezal (Branco et al. 1994). Assim, este trabalho visa contribuir com o conhecimento da riqueza de espécies de cianobactérias que compõem as comunidades marinhas bentônicas brasileiras. 


\section{Material e métodos}

As coletas foram realizadas durante o período de 1999 a 2003, principalmente na zona supralitorânea onde há maior quantidade de massas macroscópicas de cianobactérias. $\mathrm{Na}$ zona entremarés foram coletadas macroalgas para o estudo das populações epífitas, bem como raspagem de rochas e conchas. Todas as amostras foram preservadas em formalina a $4 \%$. Posteriormente, o material foi separado sob lupa e as características morfológicas pertinentes a cada grupo foram observadas ao microscópio fotônico (Zeiss), com sistema de epifluorescência, câmara-clara, máquina fotográfica e ocular de medição acoplados. Fotomicrografias foram obtidas com o auxílio de programa de captura de imagem (AxioVision) e câmera digital (Sony) acoplada ao fotomicroscópio (Axioskop 2, Zeiss). Todas as populações encontradas (mínimo de 30 indivíduos) foram medidas, desenhadas e/ou fotografadas.

As cianobactérias foram coletadas ao longo do litoral paulista no Município de Cananéia, Ilha da Casca $\left(25^{\circ} 04^{\prime} 45^{\prime \prime} \mathrm{S}\right.$ e 4557’02” W); Município de São Sebastião, Ilha das Couves

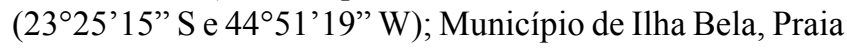

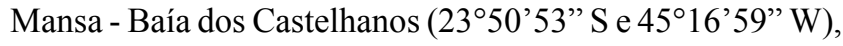
Ilha Vitória ( $\left.23^{\circ} 47^{\prime} 02^{\prime \prime} \mathrm{S} \mathrm{e} 45^{\circ} 01^{\prime} 07^{\prime \prime} \mathrm{W}\right)$, Praia das Anchovas $\left(23^{\circ} 45^{\prime} 07^{\prime}\right.$ 'S e $45^{\circ} 01^{\prime} 02^{\prime \prime}$ W) e Praia do Saco do Eustáquio ( $23^{\circ} 44^{\prime} 53^{\prime \prime} \mathrm{S}$ e $\left.45^{\circ} 20^{\prime} 50^{\prime \prime} \mathrm{W}\right)$ e no Município de Ubatuba, Ilha da Rapada $\left(23^{\circ} 25^{\prime} 05^{\prime \prime}\right.$ S e $44^{\circ} 54^{\prime} 19^{\prime \prime}$ W) e Ilha Anchieta

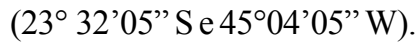

O sistema de classificação adotado foi o de Komárek \& Anagnostidis (1989, 1998, 2005).

O material estudado foi depositado no Herbário Cientifico do Estado "Maria Eneyda P. Kauffmann Fidalgo", Instituto de Botânica de São Paulo (SP).

\section{Resultados e Discussão}

Chave para identificação dos táxons estudados:

1. Células isoladas ou formando colônias e agregados

2. Divisão celular por fissão binária em um plano .

Aphanothece variabilis

2. Divisão celular por fissão binária em dois, três ou mais planos

3. Divisão celular em dois planos

4. Colônias irregulares, células dispostas irregularmente na mucilagem Aphanocapsa littoralis

4. Colônias tabulares, células dispostas paralelamente em uma camada .... Merismopedia mediterranea

3. Divisão celular em três planos ou mais

5. Talo com fileiras de células formando pseudofilamentos..... Cyanodermatium gonzaliensis

5. Células isoladas ou formando colônias

6. Talo colonial; baeocitos ausentes Gloeocapsopsis crepidinum

6. Talo freqüentemente formado por células isoladas; baeocitos presentes ...... Xenococcus pallidus

1. Células dispostas em fileiras formando tricomas unisseriados

7. Tricomas homocitados

8. Células pelo menos cinco vezes mais largas do que longas

9. Filamentos com mais de um tricoma por bainha

10. Tricomas com 14-22 $\mu \mathrm{m}$ de diâmetro Blennothrix glutinosa

10. Tricomas com 9-12 $\mu \mathrm{m}$ de diâmetro Blennothrix lyngbyacea

9. Filamentos sempre com um só tricoma por bainha

11. Septos não granulados; tricomas com 14-20 $\mu \mathrm{m}$ de diâmetro

L. aestuarii

11. Septos freqüentemente granulados; tricomas menores que $14 \mu \mathrm{m}$ de diâmetro

12. Ausência de bainha. Oscillatoria nigro-viridis

12. Presença de bainha

13. Célula apical arredondada; tricomas com 9-13 $\mu \mathrm{m}$ de diâmetro L. confervoides

13. Célula apical cônica ou captada; tricomas com 5-10 $\mu \mathrm{m}$ de diâmetro L. semiplena

8. Células isodiamétricas ou até duas vezes mais largas do que longas ou mais longas do que largas

14. Células isodiamétricas ou até duas vezes mais largas do que longas

15. Tricomas curtos, até $40 \mu \mathrm{m}$ de comprimento, sem bainha individual e com mucilagem colonial Yonedaella lithophila

15. Tricomas longos (sempre mais de $40 \mu \mathrm{m}$ de comprimento), bainha individual presente, um só tricoma por bainha Symploca atlantica 
14. Células até duas vezes mais longas do que largas

16. Tricomas espiralados

Spirulina labyrinthiformis

16. Tricomas retos ou apenas curvos

17. Apenas um tricoma por bainha

Phormidium cf. corium

17. Vários tricomas dentro de uma bainha

18. Bainha aberta

Microcoleus chthonoplastes

18. Bainha geralmente fechada

Trichocoleus tenerrimus

7. Tricomas heterocitados, sem ramificações ou apenas com falsas ramificações

19. Tricomas isopolares

20. Falsas ramificações ausentes

Hydrocoryne spongiosa

20. Falsas ramificações presentes

21. Ápices arredondados, não atenuados

Scytonema siculum

21. Ápices atenuados em pêlos

Kyrtuthrix maculans

19. Tricomas heteropolares

22. Tricomas não atenuados

Microchaete aeruginea

22. Tricomas atenuados

23. Tricomas isolados ou emaranhados

Calothrix crustacea

23. Tricomas organizados em colônias hemisféricas

Rivularia atra

\section{CHROOCOCCALES}

\section{CHROOCOCCACEAE}

Gloeocapsopsis crepidinum (Thur.) Geitler ex Komárek, Bull. Nat. Sci. Mus. Tokyo 19(1): 23.1993 三 Protococcus crepidinum Thur., Mem. Soc. Nat. Cherbourg 2: 388. 1854.

Figura 1

Colônias gelatinosas, irregulares, formando pacotes, verde-escuras a verde-azuladas, densamente agregadas. Bainha mucilaginosa, claramente delimitada, às vezes, lamelada, hialina quando em colônias individuais, tornando-se amarelada quando as colônias estão reunidas. Células subesféricas, 2,5-4 $\mu \mathrm{m}$ diâm.; conteúdo celular verde azulado. Divisão celular em três ou mais planos.

Material examinado: BRASIL: SÃo PAUlo: Município de Cananéia, Ilha da Casca, 14-IV-2002, S.M.P.B. Guimarães et al. s.n. (SP365637).

Referências para o litoral brasileiro: como Gloeocapsa crepidinum (Thur.) Thur.- São Paulo, Itanhaém (Sant'Anna et al. 1995), Ubatuba (Sant'Anna 1995); Maranhão, Estreito dos Coqueiros e dos Mosquitos (Nogueira \& Ferreira-Correia 2001).

Gloeocapsopsis crepidinum ocorreu em meio à massa lodosa, sobre rocha granítica, junto com Lyngbya aestuarii Liebman ex Gomont, Microcoleus chthonoplastes Zanardini ex Gomont e Symploca atlantica Gomont, na porção superior da zona entremarés. O gênero Gloeocapsopsis, proposto por
Geitler (1925), foi revalidado por Komárek (1993). Segundo este último autor, o gênero Gloeocapsopsis é distinto de Gloeocapsa (e de todas as Microcystaceae) pela forma das células vegetativas, tipo de divisão celular e pelo envelope mucilaginoso individual que pode ser densamente lamelado, mas nunca amplo. O material identificado para o litoral do Estado do Rio de Janeiro, como Gloeocapsa crepidinum (Baeta-Neves 1991) que produz baeocitos, deve pertencer ao gênero Myxosarcina.

\section{HYDROCOCCACEAE}

Cyanodermatium gonzaliensis H. Leon-Tejera et al., Algol. Stud. 109: 365. 2003.

Figuras 2-3

Colônias mucilaginosas, achatadas, dispostas em camadas crostosas como um filme fino sobre o substrato, delimitadas por firme mucilagem, cerca de $40 \mu \mathrm{m}$ de espessura. Células dispostas radialmente em uma única camada prostrada originando a porção ereta do talo; porção ereta composta de fileiras pseudofilamentosas arranjadas mais ou menos paralelamente, perpendicularmente ao substrato, com até sete células de altura. Bainha fina, geralmente coalescente, envolvendo cada célula. Células irregularmente poligonais-arredondadas, semicirculares, alongadas, 3-8 $\mu \mathrm{m}$ compr., 2-6 $\mu \mathrm{m}$ diâm. Célula apical cilíndrica, arredondada no ápice. Divisão celular em vários planos, geralmente paralelos ao substrato, originando pseudofilamentos eretos. Reprodução por 
células solitárias liberadas da parte terminal do talo (monócitos).

Material examinado: BRASIL: São PAUlo: Município de Ilha Bela, Praia das Anchovas, 14-III-2001, L.M.B. Crispino \& C.L. Sant'Anna s.n. (SP365641).

Referências para o litoral brasileiro: como Entophysalis sp. - São Paulo, Itanhaém (Sant'Anna et al. 1995).

Esta é a primeira citação do gênero Cyanodermatium para o Brasil. León-Tejera et al. (2003) descreveram Cyanodermatium gonzaliensis para o litoral de Oaxaca, México, crescendo sobre pedras sombreadas do supralitoral, cerca de seis a sete metros acima do nível do mar, o que concorda totalmente com o hábitat onde foi encontrado o material estudado. Até o momento, esta espécie é restrita à região neotropical.

\section{MERISMOPEDIACEAE}

\section{MERISMOPEDIOIDEAE}

Aphanocapsa litoralis (Hansg.) Komárek \& Anagn., Preslia 67: 16. $1995 \equiv$ Polycystis litoralis Hansg., Foslie Contr. Knowl. Mar. Alg. Norway 1: 169. 1890.

Figura 4

Colônias esféricas, elipsoidais ou irregulares, 40-80(150) $\mu \mathrm{m}$ diâm., geralmente formando subcolônias com agregados de células delimitados por mucilagem. Mucilagem colonial ampla, homogênea, incolor, margem delimitada. Células esféricas ou ovais antes da divisão, 3-4 $\mu \mathrm{m}$ diâm.; conteúdo celular verde-azulado pálido. Reprodução por fissão binária em dois planos, célulasfilha crescendo até o tamanho original antes da próxima divisão.

Material examinado: BRASIL: São PAUlo: Município de Cananéia, Ilha da Casca, 14-IV-2002, S.M.P.B. Guimarães et al. s.n. (SP365637).

Referências para o litoral brasileiro: São Paulo, Itanhaém (Sant'Anna et al. 1995), Ubatuba (Sant'Anna 1997); Rio de Janeiro, Cabo Frio (Baeta-Neves 1991).

Aphanocapsa litoralis ocorreu em meio às massas de cianobactérias filamentosas e como epífita da rodofícea Bostrychia radicans (Mont.) Mont. na zona supralitorânea dos costões rochosos.

Komárek \& Anagnostidis (1998) comentam que A. litoralis possui colônias com usualmente $30-60 \mu \mathrm{m}$ diâm. geralmente consistindo de subcolônias. Provavelmente, a grande dimensão das colônias encontradas no material estudado, até $150 \mu \mathrm{m}$ diâm., deve-se ao fato das subcolônias ocorrerem em grandes agregados, dificultando a sua separação em colônias individuais.
Merismopedia mediterranea Nägeli, N. Denkschr. Allg. Schweiz. Ges. Naturw. 10: 139. 1849 $\equiv$ Merismopedia glauca f. mediterranea (Nägeli) Collins in Collins, Holden \& Setchell. 1651. 1910.

Figura 5

Colônias tabulares, monostromáticas, geralmente até 64 células dispostas em um único plano, quadradas ou tabulares, 42-64 $\mu \mathrm{m}$ diâm. Mucilagem colonial incolor, amorfa, fina, margem usualmente distinta. Células esféricas, levemente ovais antes da divisão, 4-6 $\mu \mathrm{m}$ diâm.; conteúdo celular verde-azulado pálido. Reprodução por fissão binária em dois planos perpendiculares ao plano da colônia, células-filha crescendo até o tamanho original antes da próxima divisão.

Material examinado: BRASIL: São PaUlo: Município de Ilha Bela, Praia das Anchovas, 14-VIII-2001, L.M.B. Crispino \& C.L. Sant'Anna s.n. (SP365641).

Referências para o litoral brasileiro: como Merismopedia elegans var. marina Lagerh. - Rio de Janeiro, Cabo Frio (Baeta-Neves 1991).

Esta é a primeira citação da ocorrência da espécie para o litoral do Estado de São Paulo. Merismopedia mediterranea ocorreu em meio às massas de cianobactérias filamentosas na zona supralitorânea dos costões rochosos. Baeta-Neves (1991) citou, para o Estado do Rio de Janeiro, M. elegans var. marina, entretanto, Komárek \& Anagnostidis (1998) mostraram que material marinho não pertence à $M$. elegans. $\mathrm{O}$ material encontrado por Baeta-Neves (1991) é morfometricamente muito semelhante ao material estudado, o que nos leva a considerá-lo como pertencente à mesma espécie. Atualmente M. elegans var. marina é o basiônimo de Microcrocis marina (Lagerh.) Komárek \& Anagn. O gênero Merismopedia normalmente possui células esféricas ou quando levemente alongadas estão arranjadas com seu eixo maior no plano da colônia. Diferentemente, o gênero Microcrocis possui as células alongadas arranjadas com seu eixo maior num plano perpendicular ao plano da colônia. Contudo, como mostra a figura 5, o material estudado pertence ao gênero Merismopedia.

\section{SYNECHOCOCCACEAE}

\section{APHANOTHECOIDEAE}

Aphanothece variabilis (J. Schiller) Komárek, Folia Geobot. Phytotaxon. 30: 82. 1995 三 Cyanogastrum variabile J. Schiller, Ergebn. Dtsch. Limnol. VenezuelaExped. 1952. 1: 203. 1956.

Figuras 6-7 
Colônias esféricas, discoidais ou alongadas, com células densamente aglomeradas no centro ou algumas vezes na margem colonial ou ainda em grupos irregulares. Mucilagem colonial ampla, homogênea, incolor, margem usualmente delimitada. Células cilíndrico-ovais ou elipsoidais, 3-4,5 $\mu \mathrm{m}$ diâm., 5-6 $\mu \mathrm{m}$ compr.; células 1,5 vez mais longas do que largas; conteúdo celular verde azulado pálido. Reprodução por fissão binária em um plano, células-filha crescendo até o tamanho original antes da próxima divisão.

Material examinado: BRASIL: São Paulo: Município de Cananéia, Ilha da Casca, 14-IV-2002, S.M.P.B. Guimarães et al. s.n. (SP365637); Município de Ubatuba, Ilha Anchieta, 28-V-2002, M.T. Fujii et al. s.n. (SP365644).

Referências para o litoral brasileiro: como Aphanothece castagnei (Bréb.) Rabenh. - São Paulo, Itanhaém (Sant'Anna et al. 1995), Ilha do Cardoso (Branco et al. 1996); Rio de Janeiro, Cabo Frio (BaetaNeves 1991); Pernambuco, Ilha de Itamaracá (Branco et al. 2003). Como Aphanothece variabilis - Rio de Janeiro, Lagoa de Carapebus (Azevedo et al. 1999).

Aphanothece variabilis ocorreu em meio às massas de cianobactérias filamentosas na zona supralitorânea dos costões rochosos. Komárek \& Anagnostidis (1998) reconheceram A. castagnei (Bréb.) Rabenh. como espécie aerofítica, de ocorrência comum particularmente em montanhas e descartam a identificação desta espécie em ambientes aquáticos. Os autores, entretanto, identificam $A$. variabilis como de ocorrência comum no litoral das ilhas do Caribe e de distribuição pantropical. Nossos resultados confirmam o observado por Komárek \& Anagnostidis (1998).

\section{XENOCOCCACEAE}

Xenococcus pallidus (Hansg.) Komárek \& Anagn., Preslia 67: 22. 1995 三Xenococcus schousboei var. pallidus Hansg., Österr. Zeitschr. 39: 5. 1889.

Figuras 8-9

Células isoladas ou raramente formando agregados não muito densos, epífitas, esféricas, arredondadas ou achatadas, (3-)4-6 $\mu \mathrm{m}$ diâm. Bainha hialina, individual e fina. Reprodução por fissão binária em dois ou mais planos e fissão múltipla. Baeocitos presentes, 1,0-1,5 $\mu \mathrm{m}$ diâm.

Material examinado: BRASIL: São Paulo: Município de Ilha Bela, Ilha Vitória, 13-III-2001, L.M.B. Crispino \& C.L. Sant'Anna s.n. (SP365640).

Esta é a primeira citação de ocorrência da espécie para o litoral Atlântico sul. Xenococcus pallidus ocorreu como epífita de Lyngbya semiplena J. Agardh ex Gomont. O gênero Xenococcus é de ocorrência comum como epífita em outras cianobactérias ou macroalgas: Lyngbya majuscula Harv. ex Gomont (Sant'Anna 1997), Microcoleus chthonoplastes Zanardini ex Gomont (Baeta-Neves \& Tribuzi 1992), (Sant'Anna et al. 1995), (Branco et al. 2003), Scytonema siculum Borzi ex Bornet \& Flahault (Sant'Anna et al. 1995), Bachelotia antillarum (Grunow) Gerloff (Sant'Anna et al. 1995), Caulerpa sp. (Sant'Anna et al. 1995), Bostrychia sp. (Baeta-Neves \& Tribuzi 1992), (Branco et al. 1996).

\section{OSCILLATORIALES}

\section{BORZIACEAE}

Yonedaella lithophila (Erceg.) Umezaki, Taxon 11(6): 204. $1962 \equiv$ Isocystis litophila Erceg., Jugosl. Akad. Znan. Umjetn. 244: 160. 1932.

Figura 28

Colônias microscópicas, esféricas, até $70 \mu \mathrm{m}$ diâm. Mucilagem hialina, levemente amarelada, densa, envolvendo numerosos tricomas. Tricomas curtos, até $40 \mu \mathrm{m}$ compr., curvados, constritos, não atenuados, 1-2 $\mu \mathrm{m}$ diâm. Células isodiamétricas, elipsoidais a quase esféricas, conteúdo celular homogêneo. Septos não granulados. Conteúdo celular azul-esverdeado pálido. Célula apical arredondada, hemisférica.

Material examinado: BRASIL: São Paulo: Município de Ilha Bela, Ilha Vitória, 13-III-2001, L.M.B. Crispino \& C.L. Sant'Anna s.n. (SP365640), Praia das Anchovas, 14-III-2001, L.M.B. Crispino \& C.L. Sant'Anna s.n. (SP365641).

Referências para o litoral brasileiro: como Isocystis litophila Erceg. - São Paulo, Itanhaém (Sant'Anna et al. 1985). Como Yonedaella lithophila - São Paulo, Ilha do Cardoso (Branco et al. 1997); Pernambuco, Ilha de Itamaracá (Branco et al. 2003).

Yonedaella litophila é uma espécie epilítica, ocorrendo na zona supralitorânea dos costões rochosos de granito, junto com Kyrtuthrix maculans (Gomont) Umezaki e Calothrix crustacea Thur. ex Bornet \& Flahault.

\section{OSCILLATORIACEAE}

\section{OSCILLATORIOIDEAE}

Blennothrix glutinosa (Gomont ex Gomont) Anagn. ex Komárek in Anagnostidis, Preslia 73: 373. 2001 $\equiv$ Hydrocoleum glutinosum Gomont ex Gomont, Ann. Sci. Nat. Bot. 15: 339. 1892.

Figura 10 

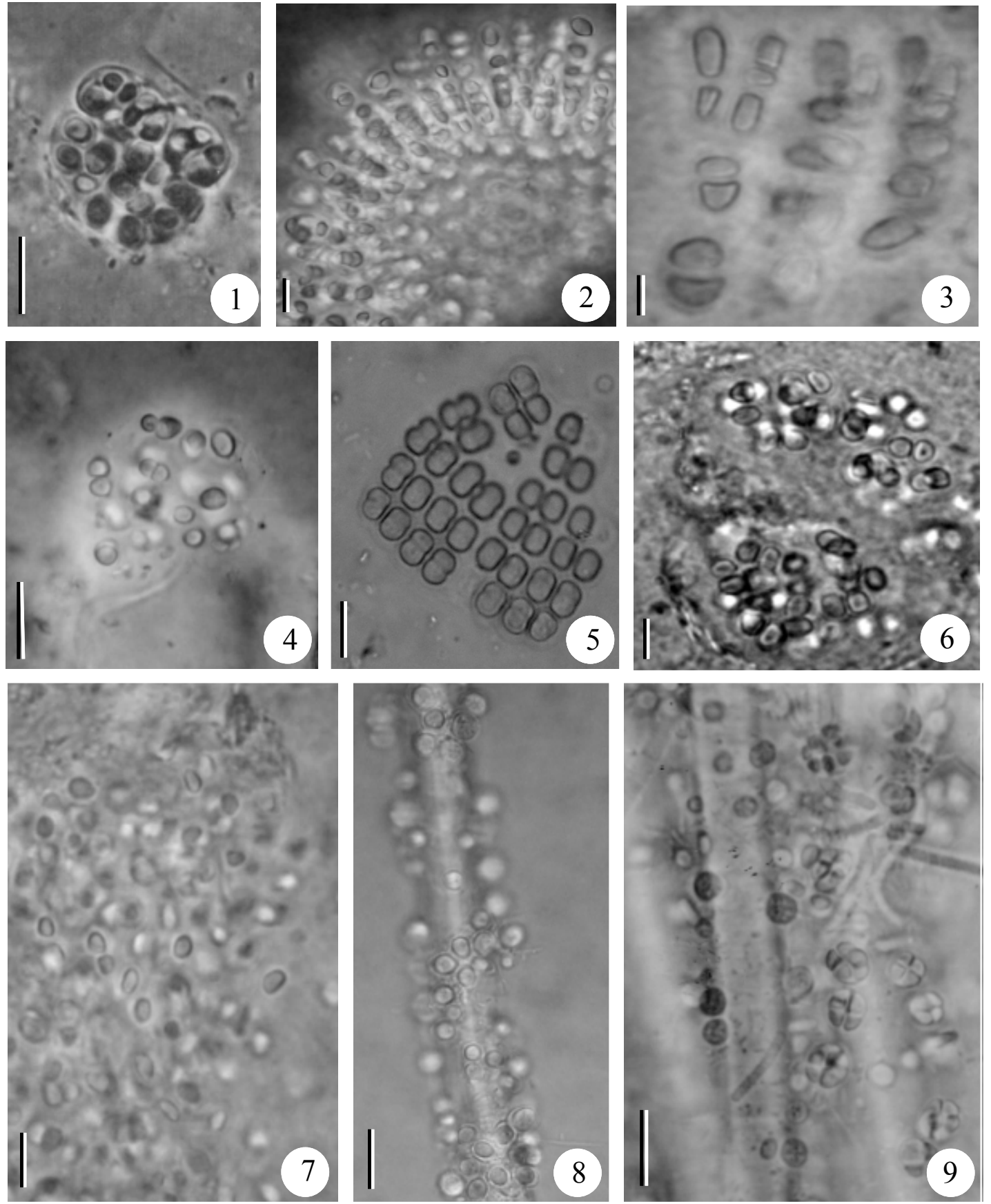

Figuras 1-9. 1. Gloeocapsopsis crepidinum (Thur.) Geitler ex Komárek. Aspecto geral das colônias com bainha incolor a amarelada. 2-3. Cyanodermatium gonzaliensis H. Leon-Tejera et al. 2. Colônia com fileiras de células pseudofilamentosas arranjadas paralelamente. 3. Detalhe dos pseudofilamentos. 4. Aphanocapsa litoralis (Hansg.) Komárek \& Anagn. Colônia com mucilagem incolor. 5. Merismopedia mediterranea Nägeli. Aspecto da colônia. 6-7. Aphanothece variabilis (J. Schiller) Komárek. Aspecto da colônia. 8-9. Xenococcus pallidus (Hansg.) Komárek \& Anagn. 8. Colônias epífitas. 9. Detalhe das células em divisão. Barras $=5 \mu \mathrm{m}(3,6$ e 7); $10 \mu \mathrm{m}(1,2,4,5$ e 9); $20 \mu \mathrm{m}(8)$.

Figures 1-9. 1. Gloeocapsopsis crepidinum (Thur.) Geitler ex Komárek. General aspect of the colonies with colourless to yellow envelopes. 2-3. Cyanodermatium gonzaliensis H. Leon-Tejera et al. 2. Colonies with pseudofilamentous parallel rows of cells. 3. Detail of pseudofilaments. 4. Aphanocapsa litoralis (Hansg.) Komárek \& Anagn. Colony with colourless mucilage. 5. Merismopedia mediterranea Nägeli. General aspect of a colony. 6-7. Aphanothece variabilis (J. Schiller) Komárek. General aspect of a colony. 8-9. Xenococcus pallidus (Hansg.) Komárek \& Anagn. 8. Epiphytic colonies. 9. Dividing cells. Bars $=5 \mu \mathrm{m}$ (3, 6 and 7$) ; 10 \mu \mathrm{m}(1,2,4,5$ and 9$) ; 20 \mu \mathrm{m}(8)$. 
Talo mucilaginoso, amorfo, verde-oliva, escuro ou amarelado. Filamentos flexuosos, 25-34 $\mu \mathrm{m}$ diâm. Bainha hialina, difluente ou não, mucilaginosa, ramificada, envolvendo 2-8 ou mais tricomas. Tricomas não constritos, 14-22 $\mu \mathrm{m}$ diâm. Células 1,5-3 $\mu \mathrm{m}$ compr., 7-9 vezes mais largas do que longas; conteúdo celular verde-claro. Septos não ou apenas levemente granulados. Célula apical com caliptra.

Material examinado: BRASIL: São PAULO: Município de Ilha Bela, Praia das Anchovas, 14-III-2001, L.M.B. Crispino \& C.L. Sant'Anna s.n. (SP365641); Praia do Saco do Eustáquio, 15-XI-2001, S.M.P.B. Guimarães et al. s.n (SP365642); Praia Mansa, 25-X-2000, M.T. Fujii et al. s.n. (SP365639).

Referências para o litoral brasileiro: como Hydrocoleum glutinosum C. Agardh ex Gomont - Rio de Janeiro, Cabo Frio (Baeta-Neves 1992).

Esta é a primeira citação de ocorrência da espécie para o litoral do Estado de São Paulo. Blennothrix glutinosa difere de B. lyngbyacea (Gomont) Anagn. \& Komárek pelo fato desta última apresentar talo fasciculado e menor diâmetro do tricoma $(9-11 \mu \mathrm{m})$. B. glutinosum ocorre como epizóica de Fissurela sp. e também em meio à feofícea Hincksia mitchelliae (Harv.) P.C. Silva.

Blennothrix lyngbyacea (Gomont) Anagn. \& Komárek, Algol. Stud. 50-53: 429. $1988 \equiv$ Hydrocoleum lyngbyaceum Kütz. ex Gomont, Ann. Sci. Nat. Bot. 15: 337.1892.

Figuras 11-12

Talo filamentoso, aveludado, fasciculado, verdeescuro a acinzentado. Filamentos emaranhados, frouxos, coalescentes, (15-)25-33 $\mu$ m diâm. Bainha hialina, firme, depois difluente, ramificada, envolvendo (2) 8 ou mais tricomas. Tricomas não constritos, 9-12 $\mu \mathrm{m}$ diâm. Células 1,5-2,5 $\mu \mathrm{m}$ compr., 5-6 vezes mais largas do que longas; conteúdo celular verde-azulado a verde-pálido. Septos geralmente granulados. Célula apical com caliptra.

Material examinado: BRASIL: São PAULO: Município de Ilha Bela, Praia das Anchovas, 14-III-2001, L.M.B. Crispino \& C.L. Sant'Anna s.n. (SP 365641); Praia do Saco do Eustáquio, 15-XI-2001, S.M.P.B. Guimarães et al. s.n. (SP365642).

Referências para o litoral brasileiro: como Hydrocoleum lyngbyaceum Kütz. ex Gomont - São Paulo, Ilha do Cardoso (Sant'Anna 1995), Santos (Yaobin 1999), Itanhaém (Sant'Anna et al. 1995); Rio de Janeiro, Cabo Frio (Baeta-Neves 1992).

Blennothrix lyngbyacea ocorreu junto com feofíceas como Colpomenia sinuosa (Roth) Derbès et Solier e Hincksia mitchelliae (Harv.) P.C. Silva. Komárek (1998) fez a validação do gênero Blennothrix (Oscillatoriaceae) transferindo parte das espécies do gênero Hydrocoleum (Phormidiaceae) para este gênero.

Lyngbya aestuarii Liebman ex Gomont, Ann. Sci. Nat. Bot. 16: 127. 1892.

Figuras 13-14

Massa filamentosa, compacta ou flocosa, pseudoramificada, estratificada ou não, verde-azulada, acinzentada, castanha a violácea. Filamentos longos, tortuosos, nunca formando fascículos, eretos, 19-41 $\mu \mathrm{m}$ diâm. Bainha inicialmente hialina, tênue, depois larga, amarelada a acinzentada, ornamentada com estrias paralelas. Tricomas não constritos, levemente atenuados ou não, (11-)14-20 $\mu \mathrm{m}$ diâm. Células 1-2 $\mu \mathrm{m}$ compr., 10-14 vezes mais largas do que longas; conteúdo celular verde azulado, acinzentado, castanho a violáceo, granulado. Septos não ou levemente granulados. Célula apical arredondada ou truncada, espessada ou captada.

Material examinado: BRASIL: São Paulo: Município de Cananéia, Ilha da Casca, 14-IV-2002, S.M.P.B. Guimarães et al. s.n. (SP365637); Município de Ilha Bela, Ilha Vitória, 13-III-2001, L.M.B. Crispino \& C.L. Sant'Anna s.n. (SP365640); Município de Ubatuba, Ilha Anchieta, 28-V-2002, M.T. Fujii et al. s.n. (SP365644).

Referências para o litoral brasileiro: São Paulo, Itanháem (Sant'Anna et al. 1985); Rio de Janeiro, Cabo Frio (Baeta-Neves 1992, Baeta-Neves \& Tribuzi 1992); Maranhão, Estreito dos Coqueiros e dos Mosquitos (Nogueira \& Ferreira-Correia 2001).

Lyngbya aestuarii ocorreu na zona supralitorânea e entremarés, em meio às massas de outras cianobactérias como Gloeocapsopsis crepidinum (Thur.) Geitler ex Komárek, Microcoleus chthonoplastes, Phormidium cf. corium Kütz. ex Gomont, Symploca atlantica e Scytonema siculum Borzi ex Bornet \& Flahault; ocorreu também como epífita de rodofíceas como Bostrychia radicans (Mont.) Mont. e como epizóica em conchas de bivalves.

O gênero Lyngbya é considerado muito variável podendo ocorrer numerosos morfo e ecótipos, particularmente nas regiões tropicais. Características como a morfologia das células terminais e da bainha, utilizadas na delimitação das espécies, são dependentes das condições ambientais (Komárek \& Anagnostidis 2005). Portanto, os autores mencionados recomendam que devem ser avaliados somente tricomas bem desenvolvidos e atenção especial deve ser dada quando 
se examina populações em fase de multiplicação através de hormogônios, onde a maioria dos tricomas ainda está pouco desenvolvida.

Lyngbya confervoides C. Agardh ex Gomont, Ann. Sci. Nat. Bot. 16: 136. 1892.

Figura 15

Talo filamentoso, fasciculado, semelhante a um pincel ou em feixes torcidos, porção decumbente intrincada depois ascendendo em fios longos, retos, firmes ou talo lodoso com aspecto de tapete, cor verdeescuro a verde-azulado. Filamentos longos, flexuosos, 12-26 $\mu \mathrm{m}$ diâm. Bainha hialina, tênue, depois levemente amarelada, difluente. Tricomas não constritos, não atenuados, 9-13 (-17) $\mu \mathrm{m}$ diâm. Células 1-2,5 $\mu \mathrm{m}$ compr., 5-9 vezes mais largas do que longas; conteúdo celular verde-azulado a verde-brilhante ou violáceo. Septos freqüentemente granulados. Célula apical arredondada, sem caliptra, raramente espessada.

Material examinado: BRASIL: São Paulo: Município de Cananéia, Ilha da Casca, 14-IV-2002, S.M.P.B. Guimarães et al. s.n. (SP365637); Município de Ilha Bela, Ilha Vitória, 13-III-2001, L.M.B. Crispino \& C.L. Sant'Anna s.n. (SP365640).

Referências para o litoral brasileiro: São Paulo, Ilha do Cardoso (Branco et al. 1997), Itanhaém (Sant'Anna et al. 1985, 1992), Ubatuba (Sant'Anna 1997); Rio de Janeiro, Cabo Frio (Baeta-Neves 1992).

Lyngbya confervoides ocorreu na zona supralitorânea e entremarés em meio às massas de cianobactérias filamentosas como Microcoleus chthonoplastes, Symploca atlantica, Calothrix crustacea e Kyrtuthrix maculans (Gomont) Umezaki.

Lyngbya semiplena J. Agardh ex Gomont, Ann. Sci. Nat. Bot. 16: 138. 1892.

Figuras 16-17

Talo filamentoso, às vezes de aspecto mucoso, em tufos emaranhados ou não, de consistência macia, cor verde-azulado-claro ou acastanhado. Filamentos longos, retos ou tortuosos, 6-17 $\mu \mathrm{m}$ diâm. Bainha inicialmente hialina, tênue, depois mais ampla. Tricomas não constritos, às vezes, levemente atenuados, 5-10 $\mu \mathrm{m}$ diâm. Células 1-2 $\mu \mathrm{m}$ compr., 5 vezes mais largas do que longas, conteúdo celular verde a castanho-claro. Septos freqüentemente granulados. Célula apical arredondada, cônica ou captada.

Material examinado: BRASIL: São Paulo: Município de São Sebastião, Ilha das Couves, 19-I-2002, L.M.B. Crispino \& C.L. Sant'Anna s.n. (SP365638); Município de Ilha Bela, Ilha Vitória, 13-III-2001, L.M.B.
Crispino \& C.L. Sant'Anna s.n. (SP365640); Praia das Anchovas, 14-VIII-2001, L.M.B. Crispino \& C.L. Sant'Anna s.n. (SP365641).

Referências para o litoral brasileiro: São Paulo, Ilha do Cardoso (Sant'Anna 1995), Itanháem (Sant'Anna et al. 1985) (Sant'Anna \& Simonetti 1992), Ubatuba (Sant'Anna 1997); Rio de Janeiro, Cabo Frio (BaetaNeves 1992); Pernambuco, Ilha de Itamaracá (Branco et al. 2003).

Lyngbya semiplena ocorreu na zona supralitorânea em meio às massas de cianobactérias como Calothrix crustacea e Scytonema siculum.

Oscillatoria nigro-viridis Thwaites ex Gomont, Ann. Sci. Nat. Bot. 16: 217. 1892.

Figura 25

Massa esponjosa, cor verde-escuro. Tricomas retos ou levemente arqueados, constritos, levemente atenuados ou não, 8-12 $\mu \mathrm{m}$ diâm. Células 1,5-3,5 $\mu \mathrm{m}$ compr., 3-5 vezes mais largas do que longas; conteúdo celular granulado, cor verde-oliva. Septos granulados. Célula apical subcapitada, espessada.

Material examinado: BRASIL: São Paulo: Município de Cananéia, Ilha da Casca 14-IV-2002, S.M.P.B. Guimarães et al. s.n. (SP365637).

Referências para o litoral brasileiro: Rio Grande do Sul, Capão da Canoa (Garcia-Baptista \& MouraBaptista 1992); São Paulo, Itanhaém (Sant'Anna et al. 1985), Ilha do Cardoso (Sant'Anna 1995); Rio de Janeiro, Cabo Frio (Baeta-Neves 1992, Baeta-Neves \& Tribuzi 1992); Pernambuco, Ilha de Itamaracá (Branco et al. 2003).

Oscillatoria nigro-viridis ocorreu na zona entremarés em meio a Trichocoleus tenerrimus (Gomont) Anagn. e Spirulina labyrinthiformis Kütz. ex Gomont.

\section{PHORMIDIACEAE}

\section{MICROCOLEOIDEAE}

Microcoleus chthonoplastes Zanardini ex Gomont, Ann. Sci. Nat. Bot. 15: 353. 1892.

Figuras 18-19

Talo filamentoso, aspecto de tapete, verde-escuro. Filamentos tortuosos, até $162 \mu \mathrm{m}$ diâm. Bainha hialina, margem irregular, espessada, difluente, aberta na extremidade, envolvendo geralmente (4-)8-10 tricomas. Tricomas constritos, 4-6 mm diâm. Células 4-8,5 $\mu \mathrm{m}$ compr.; células 1-1,5 vez mais longa do que larga; conteúdo celular verde-claro. Célula apical cônica aguda. 

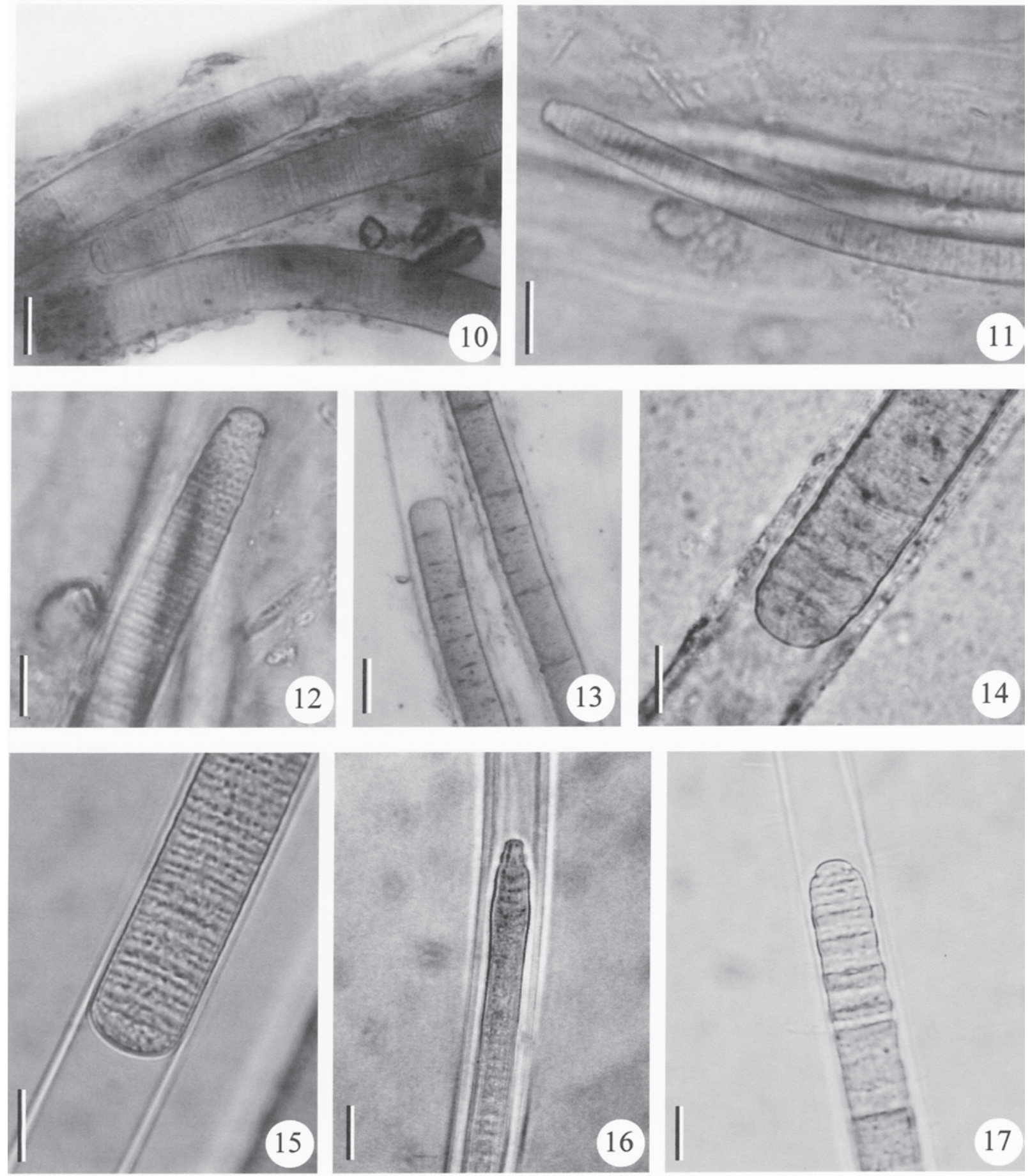

Figuras 10-17. 10. Blennothrix glutinosa (Gomont ex Gomont) Anagn. ex Komárek. Detalhe dos filamentos. 11-12. Blennothrix lyngbyacea (Gomont) Anagn. \& Komárek. 11. Detalhe dos filamentos. 12. Detalhe dos tricomas. 13-14. Lyngbya aestuarii Liebman ex Gomont. 13. Detalhe dos filamentos com bainha grossa e escura. 14. Detalhe do tricoma. 15. Lyngbya confervoides C. Agardh ex Gomont. Detalhe dos filamentos. 16-17. Lyngbya semiplena J. Agardh ex Gomont. 16. Detalhe dos filamentos. 17. Tricomas com septos granulados e ápice captado. Barras $=10 \mu \mathrm{m}(12,14,16$ e 17); $20 \mu \mathrm{m}(10,11,13$ e 15$)$.

Figures 10-17. 10. Blennothrix glutinosa (Gomont ex Gomont) Anagn. ex Komárek. Detail of filaments. 11-12. Blennothrix lyngbyacea (Gomont) Anagn. \& Komárek. 11. Detail of filaments. 12. Detail of trichomes. 13-14. Lyngbya aestuarii Liebman ex Gomont. 13. Detail of filaments with thick and dark sheaths. 14. Detail of trichomes. 15. Lyngbya confervoides C. Agardh ex Gomont. Detail of filaments. 16-17. Lyngbya semiplena J. Agardh ex Gomont. 16. Detail of filaments. 17. Trichomes with granulated cross-walls. Bars $=10 \mu \mathrm{m}(12,14,16$ and 17); $20 \mu \mathrm{m}(10,11,13$ and 15). 
Material examinado: BRASIL: São Paulo: Município de Cananéia, Ilha da Casca, 14-IV-2002, S.M.P.B. Guimarães et al. s.n. (SP365637).

Referências para o litoral brasileiro: São Paulo, Ilha do Cardoso (Sant'Anna 1995) (Branco et al. 1997), Itanhaém (Sant'Anna et al. 1995), Ubatuba (Sant'Anna 1997), Santos (Yaobin 1999); Rio de Janeiro, Cabo Frio (Baeta-Neves 1992, Baeta-Neves \& Tribuzi 1992); Pernambuco, Ilha de Itamaracá (Branco et al. 2003); Maranhão, Estreito dos Coqueiros e dos Mosquitos (Nogueira \& Ferreira-Correia 2001).

Microcoleus chthonoplastes ocorreu na zona supralitorânea e entremarés como epífita em feofíceas como Bachelotia antillarum, em meio a massa de cianobactérias como Gloeocapsopsis crepidinum, Lyngbya aestuarii, Scytonema siculum e Trichocoleus tenerrimus ou como epizóica em pequenos bivalves.

\section{PHORMIDIOIDEAE}

Phormidium cf. corium Kütz. ex Gomont, Ann. Sci. Nat. Bot. 16: 172. 1892.

Figuras 22-24

Talo filamentoso, estratificado, membranáceo, de difícil dissociação, verde-escuro-azulado ou acinzentado. Filamentos longos, flexuosos, densamente emaranhados, 4-7 $\mu \mathrm{m}$ diâm. Bainha hialina, confluente. Tricomas não constritos, não ou levemente atenuados, 4-5 $\mu \mathrm{m}$ diâm. Células 4-6 $\mu \mathrm{m}$ compr.; células 1,5 vez mais longa do que larga; conteúdo celular verde a verde-azulado, granulado ou não. Septos não granulados. Célula apical arredondada ou cônica, com ou sem espessamento externo.

Material examinado: BRASIL: São Paulo: Município de Cananéia, Ilha da Casca, 14-IV-2002, S.M.P.B. Guimarães et al. s.n. (SP365637).

Referências para o litoral brasileiro: São Paulo, Ilha do Cardoso (Branco et al. 1997), Itanhaém (Sant'Anna et al. 1985).

Phormidium cf. corium ocorreu na zona supralitorânea e entremarés dos costões rochosos em meio a outras cianobactérias como Calothrix crustacea e Trichocoleus tenerrimus.

As espécies marinhas de Phormidium descritas em Komárek \& Anagnostidis (2005) não apresentam semelhança com o material observado. Entretanto, as características morfológicas descritas por Komárek \& Anagnostidis (2005) para Phormidium corium Gomont concordam com as observadas no material estudado, embora a ocorrência de $P$. corium seja restrita a ambientes de água doce.

Symploca atlantica Gomont, Ann. Sci. Nat. Bot. 16: 109. 1892.

Figura 26

Talo com uma parte prostrada e outra em tufos eretos, coalescentes ou não, verde-escuro. Filamentos tortuosos. Bainha hialina, fina, coesiva ou levemente mucosa, um tricoma por bainha. Tricoma constrito, 4-6 $\mu \mathrm{m}$ diâm. Células sub-quadráticas a 2 vezes mais largas do que longas, 2-3 $\mu \mathrm{m}$ compr., conteúdo celular verde-brilhante, levemente granulado. Septos não granulados. Célula apical cônica, espessada.

Material examinado: BRASIL: São Paulo: Município de Cananéia, Ilha da Casca, 14-IV-2002, S.M.P.B. Guimarães et al. s.n. (SP365637).

Referências para o litoral brasileiro: São Paulo, Itanhaém (Sant'Anna et al. 1995), Ubatuba (Sant'Anna 1997).

Symploca atlantica ocorreu na zona supralitorânea e entremarés em meio a cianobactérias como Gloeocapsopsis crepidinum e Lyngbya aestuarii.

\section{PSEUDANABAENACEAE}

\section{SPIRULINOIDEAE}

Spirulina labyrinthiformis Kütz. ex Gomont, Ann. Sci. Nat. Bot. 16: 255. 1892.

Figura 27

Tricomas geralmente isolados, espiras justapostas, eixo mais ou menos reto, $1 \mu \mathrm{m}$ diâm.; conteúdo celular verde-azulado-pálido. Espiras 2-2,5 $\mu \mathrm{m}$ diâm.

Material examinado: BRASIL: São Paulo: Município de Cananéia, Ilha da Casca, 14-IV-2002, S.M.P.B. Guimarães et al. s.n. (SP365637); Município de Ilha Bela, Praia Mansa 25-X-2002, M.T. Fujii et al. s.n. (SP365639); Praia das Anchovas, 14-III-2001, L.M.B. Crispino \& C.L. Sant'Anna S.n. (SP365641); Praia do Saco do Eustáquio, 15-XI-2001, S.M.P.B. Guimarães et al. s.n. (SP365642).

Referências para o litoral brasileiro: São Paulo, Itanhaém (Sant'Anna et al. 1985), Ubatuba (Sant'Anna 1997).

Spirulina labyrinthiformis ocorreu sobre a mucilagem de outras cianobactérias filamentosas como Blennothrix glutinosa e B. lyngbyacea. Além de ocorrer também em meio a massa de Oscillatoria nigro-viridis. O material estudado ocorre isoladamente, não formando talo ou massa de tricomas, como descrito por Komarék \& Anagnostidis (2005). 


\section{SCHIZOTRICHACEAE}

Trichocoleus tenerrimus (Gomont) Anagn., Preslia 73: 369. 2001 =Microcoleus tenerrimus Gomont, Ann. Sci. Nat. Bot. 15: 355. 1892.

Figuras 20-21

Talo filamentoso, aspecto de tapete, verde-escuro. Filamentos dispersos entre outras algas, tortuosos, até $40 \mu \mathrm{m}$ diâm. Bainha hialina, levemente ornamentada, espessada, difluente, geralmente fechada na extremidade, envolvendo no mínimo 4 tricomas densamente agregados. Tricomas constritos, atenuados, 2-3 $\mu \mathrm{m}$ diâm. Células 2-5 $\mu \mathrm{m}$ compr., 1-1,7 vez mais longa do que larga; septos translúcidos, conteúdo celular verde-escuro. Célula apical cônica-aguda.

Material examinado: BRASIL: São Paulo: Município de Cananéia, Ilha da Casca, 14-IV-2002, S.M.P.B. Guimarães et al. s.n. (SP365637).

Referências para o litoral brasileiro: como Microcoleus tenerrimus Gomont São Paulo, Ilha do Cardoso (Sant'Anna 1995, Branco et al. 1997), Itanháem (Sant'Anna \& Simonetti 1992), Ubatuba (Sant'Anna 1997).

Trichocoleus tenerrimus ocorreu na zona supralitorânea e entremarés dos costões rochosos em meio a macroalgas como Porphyra sp. e com cianobactérias filamentosas como Microcoleus chtonoplastes, Phormidium cf. corium, Oscillatoria nigro-viridis e Scytonema siculum.

\section{NOSTOCALES}

\section{MICROCHAETACEAE}

\section{MICROCHAETOIDEAE}

Microchaete aeruginea Batters, J. Bot. 30: 86. 1892. Figura 29

Talo microscópico, cespitoso. Filamentos arranjados desordenadamente, curvos, flexuosos, verde-claro a amarelado. Bainha hialina, visível apenas na porção terminal do filamento, contendo um tricoma. Tricomas levemente constritos, não atenuados, 6-7 $\mu \mathrm{m}$ diâm. Células quadráticas a subquadráticas, 4-6 $\mu \mathrm{m}$ compr. Heterocitos 1-3, esféricos a hemisféricos, 7-9 $\mu \mathrm{m}$ diâm., basais.

Material examinado: BRASIL: São PaUlo: Município de Ilha Bela, Praia Mansa, 25-X-2000, M.T. Fujii et al. s.n. (SP365639).

Esta é a primeira citação de ocorrência da espécie no litoral brasileiro e também para o litoral Atlântico sul. Anteriormente, Frémy (1933) encontrou
Microchaete aeruginea na costa sul da Inglaterra. $M$. aeruginea ocorre na zona entremarés, como epífita de feofíceas como Hincksia mitchelliae (Harv.) P.C. Silva e em meio a outras cianobactérias como Hydrocoryne spongiosa Bornet \& Flahault.

\section{NOSTOCACEAE}

\section{ANABAENOIDEAE}

Hydrocoryne spongiosa Bornet \& Flahault, Ann. Sci. Nat. Bot. 5: 83. 1886.

Figuras 30-32

Talo membranoso, gelatinoso, esponjoso, verdeclaro a amarelado. Filamentos emaranhados, ramificados, até $10 \mu \mathrm{m}$ diâm. Bainha delgada, hialina, difluente, levemente estriada longitudinalmente, envolvendo um ou mais tricomas. Tricomas com $5 \mu \mathrm{m}$ diâm. Células 2-3 $\mu \mathrm{m}$ compr., 2-2,5 vezes mais largas do que longas. Heterocitos intercalares, quadráticos a arredondados, 5-6 $\mu \mathrm{m}$ diâm.

Material examinado: BRASIL: S̃̃o PAulo: Município de Ilha Bela, Praia Mansa, 25-X-2000, M.T. Fujii et al. s.n. (SP365639).

Esta é a primeira citação de ocorrência da espécie no litoral brasileiro e também para o litoral Atlântico sul. Frémy (1933) observou, para a costa Européia, Hydrocoryne spongiosa como epífita em plantas submersas, o que também foi observado no material estudado. H. spongiosa ocorreu na zona entremarés como epífita de feofíceas como Hincksia mitchelliae e em meio a massa de cianobactérias como Microchaete aeruginea.

\section{SCYTONEMATACEAE}

Kyrtuthrix maculans (Gomont) Umezaki, Mem. Coll. Agr. Kyoto Univ. vol. especial: 64. 1958 $\equiv$ Brachytrichia maculans Gomont, Bot. Tidsskrift. 24: 210. 1901.

Figuras 33-34

Talo com aspecto de almofada, arredondado, gelatinoso, escorregadio, de difícil dissociação, verdeazulado. Filamentos em forma de U, paralelos, confluentes, como um leque, 18-23 $\mu \mathrm{m}$ diâm. Bainha firme, ampla, anastomosada, hialina, amarelada na porção superior do talo. Tricomas constritos, atenuados, verde-azulados, 3-5,5 $\mu \mathrm{m}$ diâm. Células irregulares, arredondadas a quadráticas, $2-5 \mu \mathrm{m}$ compr. Heterocitos intercalares, quadráticos a arredondados, achatados, 3-9 $\mu \mathrm{m}$ diâm., 2-5 $\mu \mathrm{m}$ compr.

Material examinado: BRASIL: São Paulo: Município de Ilha Bela, Ilha Vitória, 13-III-2001, L.M.B. 

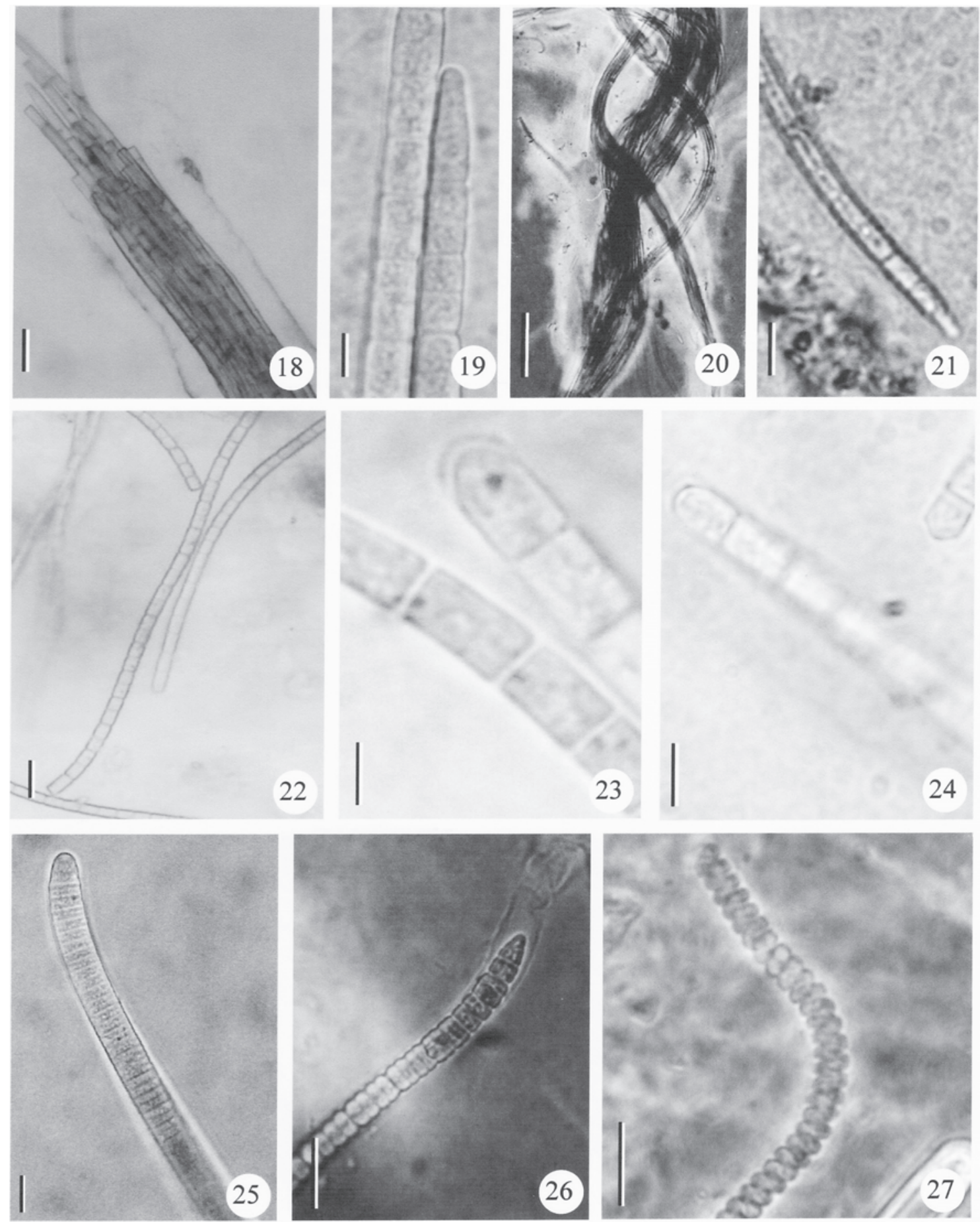

Figuras 18-27. 18-19. Microcoleus chthonoplastes Zanardini ex Gomont. 18. Aspecto geral. 19. Detalhe dos tricomas. 20-21. Trichocoleus tenerrimus (Gomont) Anagn. 20. Aspecto geral. 21. Detalhe dos tricomas. 22-24. Phormidium cf. corium Kütz. ex Gomont. 22. Aspecto geral da massa filamentosa. 23-24. Detalhe dos tricomas. 25. Oscillatoria nigro-viridis Thwaites ex Gomont. Detalhe do tricoma. 26. Symploca atlantica Gomont. Detalhe do filamento. 27. Spirulina labyrinthiformis Kütz. ex Gomont. Detalhe do tricoma. Barras $=5 \mu \mathrm{m}(19,21,23$ e 27); $10 \mu \mathrm{m}(20,22,24,25$ e 26); $20 \mu \mathrm{m}$ (18).

Figures 18-27. 18-19. Microcoleus chthonoplastes Zanardini ex Gomont. 18. General aspect. 19. Detail of trichomes. 20-21. Trichocoleus tenerrimus (Gomont) Anagn. 20. General aspect. 21. Detail of trichomes. 22-24. Phormidium cf. corium Kütz. ex Gomont. 22. View of the filamentous mats. 23-24. Detail of trichomes. 25. Oscillatoria nigro-viridis Thwaites ex Gomont. Detail of trichomes. 26. Symploca atlantica Gomont. Detail of a filament. 27. Spirulina labyrinthiformis Kütz. ex Gomont. Detail of a trichome. Bars $=5 \mu \mathrm{m}(19,21,23$ and 27); $10 \mu \mathrm{m}(20,22,24,25$ and 26); $20 \mu \mathrm{m}(18)$. 

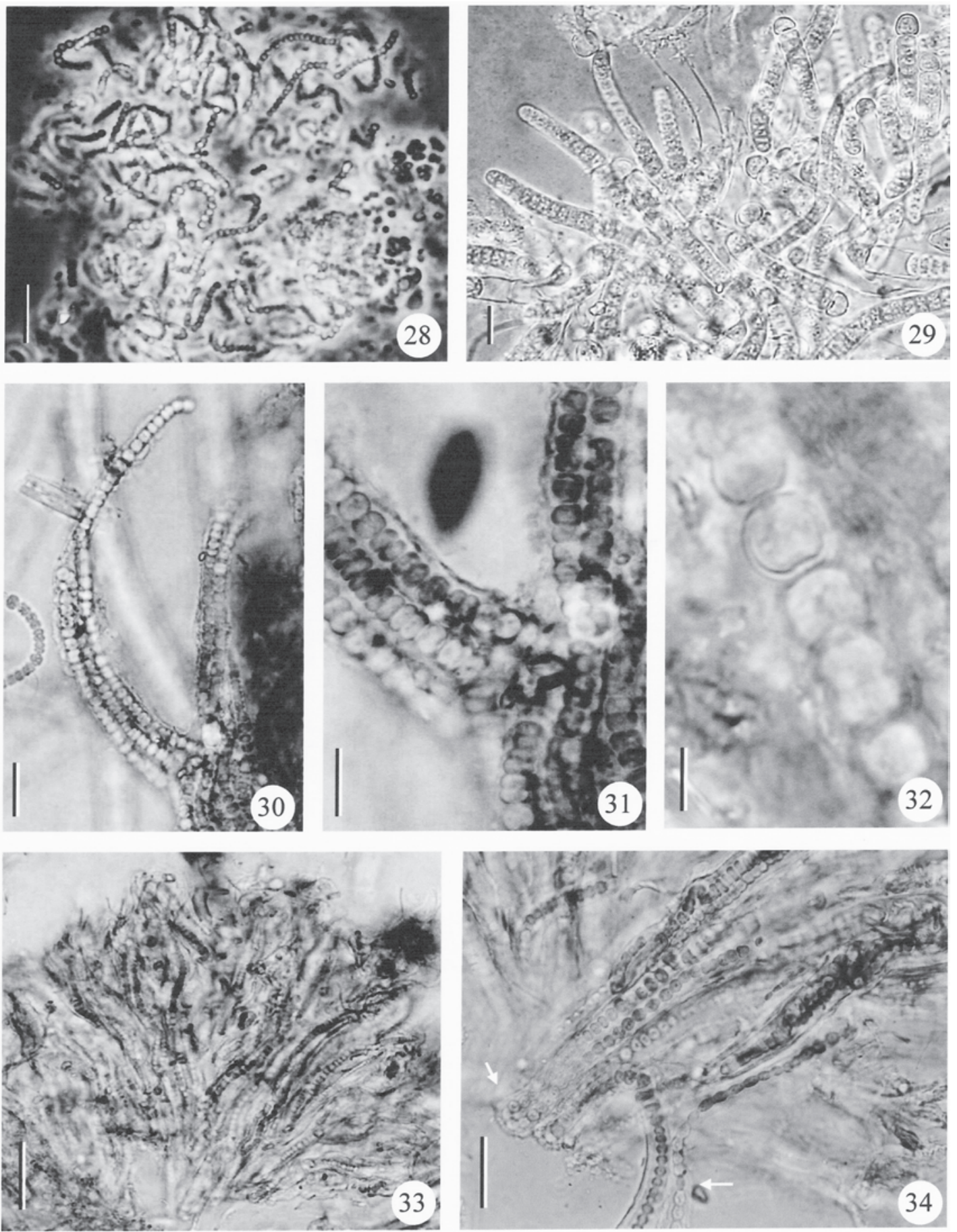

Figuras 28-34. 28. Yonedaella lithophila (Erceg.) Umezaki. Aspecto geral dos tricomas. 29. Microchaete aeruginea Batters. Aspecto geral dos filamentos. 30-32. Hydrocoryne spongiosa Bornet \& Flahault. 30. Aspecto geral dos tricomas dentro da bainha ramificada. 31. Detalhe dos tricomas. 32. Detalhe do heterocito. 33-34. Kyrtuthrix maculans (Gomont) Umezaki. 33. Aspecto geral dos filamentos. 34. Detalhe do filamento em forma de U e heterocito (setas). Barras $=5 \mu \mathrm{m}(32) ; 10 \mu \mathrm{m}(29$ e 31$) ; 20 \mu \mathrm{m}(30$, 31 e 34$) ; 50 \mu \mathrm{m}(33)$.

Figures 28-34. 28. Yonedaella lithophila (Erceg.) Umezaki. Colony with many trichomes inside the mucilage. 29. Microchaete aeruginea Batters. General aspect. 30-32. Hydrocoryne spongiosa Bornet \& Flahault. 30. View of the trichomes inside the branched sheat. 31. Detail of the trichomes. 32. Detail of the heterocyte. 33-34. Kyrtuthrix maculans (Gomont) Umezaki. 33. General aspect. 34. Detail of the filament forming characteristics loops and heterocyte (arrows). Bars $=5 \mu \mathrm{m}(32) ; 10 \mu \mathrm{m}(29$ and 31); $20 \mu \mathrm{m}(30,31$ and 34$) ; 50 \mu \mathrm{m}(33)$. 
Crispino \& C.L. Sant'Anna s.n. (SP365640), Praia das Anchovas, 14-III-2001, L.M.B. Crispino \& C.L. Sant 'Anna s.n. (SP365641); Município de Ubatuba, Ilha da Rapada, 5-XI-1999, N.S. Yokoya et al. s.n. (SP365643).

Referências para o litoral brasileiro: São Paulo, Ilha do Cardoso (Sant'Anna 1995), Itanhaém (Sant'Anna et al. 1985), Ubatuba (Sant'Anna 1997); Rio de Janeiro, Cabo Frio (Baeta-Neves 1992).

Kyrtuthrix maculans é uma espécie epilítica, ocorrendo na zona supralitorânea dos costões rochosos de granito, em meio a massa de cianobactérias como Lyngbya aestuarii, Yonedaella litophila e Calothrix crustacea.

Scytonema siculum Borzi ex Bornet et Flahault, Ann. Sci. Nat. Bot. 5: 96.1888

Figuras 35-36

Talo cespitoso, negro a verde-escuro. Filamentos de consistência dura, frouxamente emaranhados, 25-42 $\mu \mathrm{m}$ diâm. Bainha espessa, geralmente amarelada. Tricomas constritos, raramente com falsas ramificações, verde-azulado, 13-22 $\mu \mathrm{m}$ diâm. Heterocitos intercalares, quadráticos, retangulares a esféricos, 10-22 $\mu \mathrm{m}$ diâm., 14-30 $\mu \mathrm{m}$ compr.

Material examinado: BRASIL: São PAulo: Município de Cananéia, Ilha da Casca, 14-IV-2002, S.M.P.B. Guimarães et al. s.n. (SP365637); Município de Ubatuba, Ilha da Rapada, 5-V-1999, N.S. Yokoya et al. s.n. (SP365643), Ilha Anchieta, 28-V-2002, M.T. Fujii s.n. (SP365644).

Referências para o litoral brasileiro: São Paulo, Ilha do Cardoso (Sant'Anna 1995), Itanhaém (Sant'Anna et al. 1985), Ubatuba (Sant'Anna 1997).

Scytonema siculum ocorreu na zona supralitorânea dos costões rochosos como um tapete sobre rocha granítica formando faixa negra ou verde-escura, em meio às massas de cianobactérias filamentosas como Lyngbya semiplena, Microcoleus chthonoplastes, Trichocoleus tenerrimus e Calothrix crustacea.

\section{RIVULARIACEAE}

Calothrix crustacea Thur. ex Bornet \& Flahault, Ann. Sci. Nat. Bot. 3: 359. 1886.

Figuras 37-38

Talo aveludado, negro ou verde-escuro. Filamentos mais largos na base, curvados ou não na porção basal, 10-24 $\mu \mathrm{m}$ diâm. na base, 4-15 $\mu \mathrm{m}$ diâm. no ápice. Bainha espessa, hialina nos filamentos jovens, depois amarelada, coalescente ou não, freqüentemente terminando antes do tricoma. Tricomas geralmente constritos, atenuados, raramente pseudoramificados, geralmente terminando em pêlo hialino, verdes a verdeazulados, 6-13 $\mu \mathrm{m}$ diâm. base, 3-7 $\mu \mathrm{m}$ diâm. ápice. Células 1,5-3 $\mu \mathrm{m}$ compr. Heterocitos basais ou intercalares, esféricos a quadráticos, verde a amarelados, 10-15 $\mu \mathrm{m}$ compr., 6-15 $\mu \mathrm{m}$ diâm.

Material examinado: BRASIL: São Paulo: Município de Cananéia, Ilha da Casca, 14-IV-2002, S.M.P.B. Guimarães s.n. (SP365641); Município de Ilha Bela, Ilha Vitória, 13-III-2001, L.M.B. Crispino \& C.L. Sant'Anna s.n. (SP365640), Praia das Anchovas, 14-III-2001, L.M.B. Crispino \& C.L. Sant'Anna s.n. (SP365641).

Referências para o litoral brasileiro: São Paulo, Itanhaém (Sant'Anna et al. 1985); Rio de Janeiro, Cabo Frio (Baeta-Neves 1992).

Calothrix crustacea ocorreu na porção superior da zona entremarés e na zona supralitorânea dos costões rochosos formando faixa negra ou verde-escura, como película fina, em meio à massa filamentosa de cianobactérias como Lyngbya aestuarii, Yonedaella litophila e Kyrtuthrix maculans.

As características morfológicas que separam as espécies de Calothrix, principalmente C. crustacea e C. scopulorum, foram amplamente discutidas na literatura. Segundo diversos autores como Bornet \& Flahault (1886), Setchell \& Gardner (1919) e Frémy (1933), C. scopulorum diferencia-se por possuir filamentos mais curtos e estreitos, heterocitos somente basais e habitar a zona supralitorânea. Por outro lado, C. crustacea possui filamentos mais longos e largos, heterocitos basais e intercalares e ocupa a porção superior da zona entremarés. Entretanto, outros autores consideraram $C$. scopulorum como sinônimo de C. crustacea, como Fan (1956) que estudou material de herbário e considerou que C. scopulorum é uma forma de crescimento de C. crustacea. Darley (1967) demonstrou que C. scopulorum em cultura apresenta heterocitos intercalares, pelos hialinos e ramificação do tipo Scytonema. Em oposição, Umezaki (1961) reconheceu ambas as espécies baseando-se em diferenças no padrão de ramificação e do hábitat. Watanabe \& Kurogi (1975) compararam estatisticamente as características morfológicas das populações em campo e em cultura e concluíram que C. crustacea e C. scopulorum devem ser tratadas como espécies distintas, sendo que as características morfológicas que as diferenciam são: o comprimento e o diâmetro do filamento, a localização do heterocito no filamento e as diferenças no hábitat. 

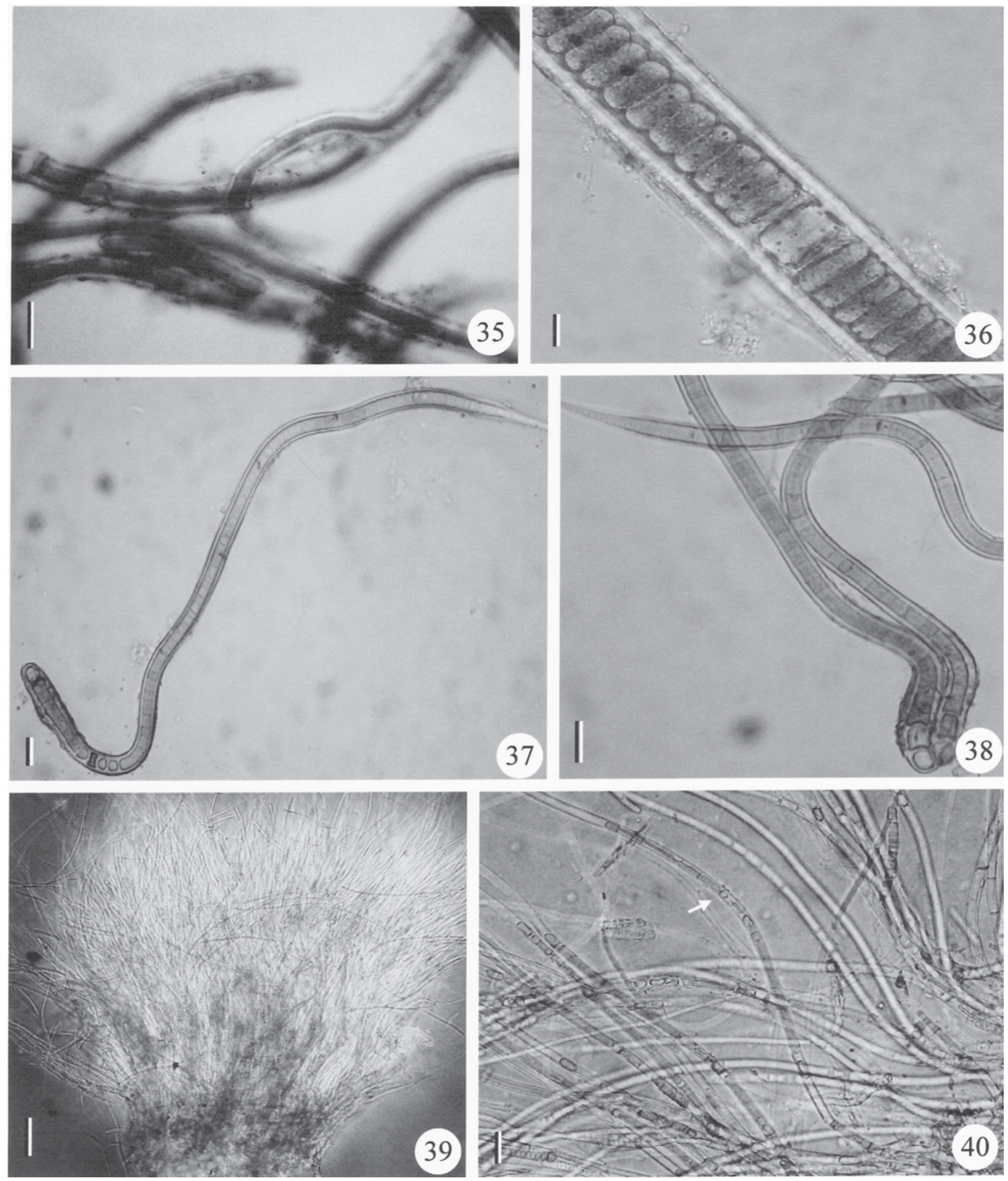

Figuras 35-40. 35-36. Scytonema siculum Borzi ex Bornet \& Flahault. Aspecto dos filamentos com falsa ramificação. 36. Detalhe do filamento com heterocito. 37-38. Calothrix crustacea Thur. ex Bornet \& Flahault. Detalhe dos filamentos com heterocito basal e intercalar. 39-40. Rivularia atra Roth. 39. Aspecto geral da massa filamentosa. 40. Detalhe do filamento com heterocito intercalar (seta). Barras $=10 \mu \mathrm{m}(36) ; 20 \mu \mathrm{m}(37$ e 38 e 40$) ; 50 \mu \mathrm{m}$ (35 e 39).

Figures 35-40. 35-36. Scytonema siculum Borzi ex Bornet \& Flahault. Filaments with false branched. 36. Detail of the heterocyte. 37-38. Calothrix crustacea Thur. ex Bornet \& Flahault. Detail of the filaments with basal and intercalar heterocytes. 39-40. Rivularia atra Roth. 39. View of the filamentous mats. 40. Detail of the filament with intercalar heterocyte (arrow). Bars $=10 \mu \mathrm{m}(36) ; 20 \mu \mathrm{m}(37 \mathrm{e} 38$ and 40$) ; 50 \mu \mathrm{m}$ (35 and 39). 
No material estudado, foram encontradas grandes populações de Calothrix. Ocorreram populações (Ilha Vitória) que apresentavam características típicas de C. crustacea: maior largura dos filamentos (até $24 \mu \mathrm{m}$ ) e tricomas (até $13 \mu \mathrm{m}$ ), heterocitos basais e intercalares e habitando a porção superior da zona entremarés. Também foram encontradas populações (Praia das Anchovas) com ampla variação no diâmetro dos filamentos $(10-18 \mu \mathrm{m})$ e tricomas $(6-11 \mu \mathrm{m})$, heterocitos basais e intercalares e habitando a faixa acima da porção superior da zona entremarés. Decidimos identificar o material estudado como $C$. crustacea, sendo que serão necessários estudos com outras amostras populacionais para podermos definir quais as características que melhor separam C. crustacea de C. scopulorum.

Rivularia atra Roth, Catalecta Bot. 3: 340. 1806. Figuras 39-40

Talo firme ou gelatinoso, hemisférico, solitário, confluente, verde-acinzentado. Filamentos dispostos radialmente, envolvidos em densa mucilagem, de difícil dissociação. Bainha hialina, inconspícua. Tricomas mais largos na base, mais estreitos no ápice, 4-5 $\mu \mathrm{m}$ diâm., freqüentemente terminando em pêlo hialino. Células 2-3 $\mu \mathrm{m}$ compr., células 2-2,5 vezes mais largas do que altas. Heterocitos 1-3 esféricos a quadráticos, na base do tricoma ou intercalares, 5-13 compr., 5-7 $\mu$ m diâm.

Material examinado: BRASIL: SÃo PAulo: Município de Ilha Bela, Praia Mansa, 25-X-2000, M.T. Fujii s.n. (SP365639).

Referências para o litoral brasileiro: primeira citação de ocorrência da espécie.

Rivularia atra foi observada por Halperin (1967) para o litoral de Puerto Deseado, Santa Cruz, Argentina, como epilítica, formando talos agregados ou solitários. O material estudado não concorda com o observado por Halperin (1967), pois foi encontrado como epizóico em conchas de Fissurela sp., concordando com a descrição apresentada por Bornet \& Flahault (1886) que é o "starting point" do grupo das cianobactérias heterocitadas.

Os resultados obtidos mostram a ocorrência de 24 espécies de cianobactérias em ilhas do litoral paulista. A ordem Oscillatoriales foi representada por 12 espécies (50\%) e Nostocales e Chrooccoccales por seis espécies cada uma (25\%).

Entre as espécies identificadas, quatro são novas ocorrências para o litoral Atlântico sul: Cyanodermatium gonzaliensis, Xenococcus pallidus, Microchaete aeruginea e Hydrocoryne spongiosa. Rivularia atra está sendo referida pela primeira vez para o litoral brasileiro. Nove táxons $(37,5 \%)$ estão sendo referidos pela primeira vez para o litoral do Estado de São Paulo: Cyanodermatium gonzaliensis, Merismopedia mediterranea, Aphanothece variabilis, Gloeocapsopsis crepidinum, Xenococcus pallidus, Blennothrix glutinosa, Microchaete aeruginea, Hydrocoryne spongiosa e Rivularia atra.

As seguintes atualizações nomenclaturais (Komárek \& Anagnostidis 2005) foram adotadas: Cyanodermatium gonzaliensis (Entophysalis sp.); Merismopedia mediteranea (M. elegans var. marina); Aphanothece variabilis (Aphanothece castagnei); Gloeocapsopsis crepidinum (Gloeocapsa crepidinum); Blennothrix glutinosa (Hydrocoleum glutinosum) e Blennothrix lyngbyacea (Hydrocoleum lyngbyaceum).

A ocorrência de Aphanothece variabilis na região estudada corrobora os dados de Komárek \& Anagnostidis (1998), que comentam que a distribuição desta espécie é pantropical. Cyanodermatium gonzaliensis tem registro de distribuição restrito, até o momento, à região neotropical.

O litoral paulista possui mais de 40 ilhas. Neste estudo, apenas oito estações de coleta foram amostradas e visitadas apenas uma vez. Mesmo assim, houve grande porcentual de novas ocorrências $(37,5 \%)$, o que deixa evidente a falta de estudos nestas áreas.

Agradecimentos - O presente trabalho é parte do projeto "Diversidade de cianobactérias marinhas bentônicas do Estado de São Paulo" pertencente ao projeto temático "Flora ficológica do Estado de São Paulo" Biota - Fapesp (processo 98/04955-3). A primeira autora agradece a Capes e ao CNPq a concessão das bolsas de doutorado.

\section{Referências bibliográficas}

ANAGNOSTIDIS, K. \& KOMARÉK, J. 1988. Modern approach to the classification system of Cyanophytes. 3 - Oscillatoriales. Algological Studies 50-53: 327-472.

ANAGNOSTIDIS, K. \& KOMARÉK, J. 2001. Nomenclatural changes in cyanoprokaryotic order Oscillatoriales. Preslia 73: 359-375.

AZEVEDO, M.T.P., SOUZA, C.A. \& MENEZES, M. 1999. Synechococcaceae (Cyanophyceae/Cyanobacteria) from a tropical brackish water lagoon, Brazil. Algological Studies 94: 45-61.

BAETA-NEVES M.H.C. 1991. Estudo das cianofíceas marinhas da região de Cabo Frio (Rio de Janeiro - Brasil), I-Chroococales. Hoehnea 18: 191-204.

BAETA-NEVES, M.H.C. 1992. Estudo das cianofíceas marinhas bentônicas da região de Cabo Frio (Rio de Janeiro, Brasil) II - Hormogonae. Revista Brasileira Biologia 52: 641-659. 
BAETA-NEVES, M.H.C. \& TRIBUZI, D. 1992. Les Cyanophycées de la mangrove de la "Ponta do Pai Vitório" de la região de Cabo Frio (RJ, Brésil). Acta Biológica Leopoldensia 14: 29-52.

BORNET, E. \& FLAHAULT, C. 1886-1888. Revision des Nostocacées heterocystées. Annales Sciencias Naturales, Botany sér. 7, 3: 323-381, 5: 51-129.

BRANCO, L.H.Z., SILVA, S.M.F. \& SANT’ANNA, C.L. 1994. Stichosiphon mangle sp.nov. from mangrove environments. Algological Studies 72: 1-7.

BRANCO, L.H.Z., SANT’ANNA, C.L., AZEVEDO, M.T.P. \& SORMUS, L. 1996. Cyanophyte flora from Cardoso Island, São Paulo State, Brazil, 1: Chroococales. Algological Studies 80: 99-111.

BRANCO, L.H.Z., SANT'ANNA, C.L., AZEVEDO, M.T.P. \& SORMUS, L. 1997. Cyanophyte flora from Cardoso Island, São Paulo State, Brazil, 2: Oscillatoriales. Algological Studies 84: 39-52.

BRANCO, L.H.Z., MOURA, A.N., SILVA, A.C. \& BITTENCOURT-OLIVEIRA, M.C. 2003. Biodiversidade e considerações biogeográficas das Cyanobacteria de uma área de manguezal do estado de Pernambuco, Brasil. Acta Botânica Brasílica 17: 585-596.

DARLEY, J. 1967. Sur quelques résults de la culture en laboratóire de deux espéces de Calothrix Agardh (Myxophycées - Rivulariacées). Compte Rendus de L'Academie des Sciences, Paris ser. D, 264: 1013-1015.

FAN, K.C. 1956. Revision of Calothrix Ag. Revue Algologique 2: 157-178.

FRÉMY, P. 1933. Les Cyanophycées des Côtes d'Europe. Memoires Societe Nationale Sciences Naturelles et Matematiques de Cherbourg 41: 1-236.

GARCIA-BAPTISTA, M. \& BAPTISTA, L.R.M. 1992. Algas psâmicas de Jardim Beira Mar, Capão da Canoa, Rio Grande do Sul. Revista Brasileira Biologia 52: 325-342.

GEITLER, L. 1932. Cyanophyceae. In Dr. L. Rabenhorst's Kryptogamenflora von Deutschlands, Österreichs und der Schweiz (R. Kolkwitz, ed.). Akademische, Verlagsgesellschft, Leipzig.

GOMONT, M. 1892. Monographie des Oscillariées (Nostocacées homocystées). Annales Sciencias Naturales Botany 15: 263-368, 16: 91-264.

HALPERIN, D.R. 1967. Cianofíceas marinas de Puerto Deseado (provincia de Santa Cruz, Argentina), II. Darwiniana 14: 273-354.

HALPERIN, D.R. 1970. Cianoficeas marinas Del Chubut (Argentina). I. Golfo San Jose, Golfo Nuevo y alrededores de Rawson. Physis 30: 33-96.

HALPERIN, D.R. 1974. Cianofíceas marinas de Puerto Deseado (provincia de Santa Cruz, Argentina), III. Physis 33: 465-482.

KOMÁREK, J. 1993. Validation of the genera Gloeocapsopsis and Asterocapsa (Cyanoprocaryota) with regard to species from Japan, Mexico and Himalayas. Bulletin of the National Science Museum, serie B, 19: 19-37.
KOMÁREK, J. 1995. Studies on the Cyanophytes (Cyanoprokaryotes) of Cuba 10. New and little known chroococcalean species. Folia Geobotanica Phytotaxonomica 30: 81-90.

KOMÁREK, J. 1998. Validity of the genus Blennothrix Kutz. 1843, and its position in the Oscillatoriacean Cyanoprokaryotes. In Anais IX Congr. Latinoamericano, II Reunião Ibero Americana, VII Reunião Brasileira de Ficologia (M.T.P. Azevedo et al. eds.). Exata, São Paulo, v.1, p. 341-352.

KOMÁREK, J. \& ANAGNOSTIDIS, K. 1989. Modern approach to the classification system of cyanophytes 4 - Nostocales. Algological Studies 56: 247-345.

KOMÁREK, J. \& ANAGNOSTIDIS, K. 1995. Nomenclatural novelties in chroococcalean cyanoprokaryotes. Preslia 67: $15-23$.

KOMÁREK， J. \& ANAGNOSTIDIS, K. 1998. Cyanoprokaryota I. Teil Chroococcales. In SüBwasserflora von Mitteleuropa. (H. Ettl, G. Gärtner, H. Heynig \& D. Mollenhauer, eds.). G. Fischer, Verlag Jena.

KOMÁREK, J. \&ANAGNOSTIDIS, K. 2005. Cyanoprokaryota II. Teil Oscillatoriales. In SüBwasserflora von Mitteleuropa. (B. Büdel, L. Krienitz, G. Gärtner \& M. Schagerl, eds.). Elsevier Gmbh, Munchen.

LEÓN-TEJERA, H., MONTEJANO, G.\& CANTORALURIZA, E. 2003. Some little known Hydrococcaceae (Cyanoprokaryota) from central Mexico. Algological Studies 109: 363-374.

NOGUEIRA, N.M.C. \& FERREIRA-CORREIA, M.M. 2001. Cyanophyceae/Cyanobacteria in red mangrove Forest at Mosquitos and Coqueiros estuaries, São Luiz, State of Maranhão, Brazil. Brazilian Journal of Biology 61: 347-356.

SANT'ANNA, C.L. 1995. Cyanophyceae marinhas bentônicas do parque Estadual da Ilha do Cardoso, SP, Brasil. Hoehnea 22: 197-216.

SANT'ANNA, C.L. 1997. Cyanophyceae marinhas bentônicas da região de Ubatuba, SP, Brasil. Hoehnea 24: 57-74.

SANT'ANNA, C.L., CORDEIRO-MARINO, M., BRAGA, M.R.A. \& GUIMARÃES, S.M.P.B. 1985. Cianobactérias marinhas bentônicas das praias de Peruíbe e dos Sonhos, Município de Itanhaém, SP, Brasil, I. Rickia 12: 89-112.

SANT'ANNA, C.L. \& SIMONETTI, C. 1992. Cianobactérias marinhas bentônicas das praias de Peruíbe e dos Sonhos, Município de Itanhaém, SP, II: espécies epiliticas e epizóicas. Revista Brasileira de Biologia 52: 515-523.

SANT'ANNA, C.L., AZEVEDO, M.T.P., BRANCO, L.H.Z., BRAGA, M.R.A., CORDEIRO-MARINO, M. \& GUIMARÃES, S.M.P.B. 1995. Cianofíceas marinhas bentônicas das praias de Peruíbe e dos Sonhos, Município de Itanhaém, SP, Brasil, III. Revista Brasileira de Biologia 55: 389-407. 
SETCHELL, W.A. \& GARDNER, N.L. 1919. The Marine algae of the Pacific coast of North America. I. Myxophyceae. University of California Publications of Botany 8: 1-138.

UMEZAKI, I. 1961. The Marine blue-green algae of Japan. Memoirs of the College of Agriculture Kyoto University 83: $1-149$
WATANABE, M. \& KUROGI, M. 1975. Taxonomic reexamination of two species of blue-gren algae, Calothrix scopulorum and C. crustacea. Botanical Magazine of Tokyo 88: 111-125.

YAOBIN, Q. 1999. Estudos sobre a variação temporal da composição de macroalgas marinhas em uma baía poluída - o caso de Santos, litoral de São Paulo, Brasil. Tese de doutorado, Universidade de São Paulo, São Paulo. 